ends of a specimen simultaneously for greater photographic convenience. The other includes an interesting examination of the transmission of a stress pulse across the boundary between two birefringent materials. Papers on instrumentation comprise two dealing with load transducer response, and one describing techniques for high speed photography. The remaining papers include a short review article on Poisson's ratio of viscoelastic materials, and a thermodynamic approach to impact analysis.

Although described as "international" none of the papers originates outside the United States. The arrangement of the papers seemed to be rather haphazard and did not appear to agree with that described in the preface. Despite a few proof reading slips the standard of presentation is generally high. However, figures 6-9 referred to by Dunaway on page 293 were not in the review copy. Being almost entirely an account of experimental work much useful information can be gleaned by the assiduous reader. Much might be missed, however, on a cursory examination, and in this respect a more detailed index and prefatory introduction would have been helpful, while the general appeal would have been widened by the inclusion of one or two major reviews. These remarks, however, must not detract from the value of this volume which has well repaid close reading. It is to be hoped that in the course of time further volumes will appear in this series.

J. M. Baxter Brown

\section{RIVER FLOWS}

Streamflow Synthesis

By Myron B. Fiering. Pp. xviii + 139. (Macmillan: London, 1967.) 70s. net.

THIs is a contribution from one of the most active members of the Harvard Water Resources Group which, for many years, has done such important research on operational methods in hydrology and, in addition to its great consulting work, has published the famous Design of WaterResource Systems and its successors. Fiering develops here the work of his chief, Harold A. Thomas, jun., on the means and variations of river flows entering water-supply reservoirs. As a result of the backwardness of flow measurement, very few of the rivers used for supply have been measured over the periods necessary for their water yield to be assessed with the engineer's usual degree of assurance. So the branch of "synthetic hydrology" now called "stochastic" has been developed to produce and test wholly artificial sequences of numbers which, however, must have the same statistical properties as the flow records themselves. From such sequences it is possible to calculate the degrees of probability with which given water yields may be obtained from reservoirs of any assumed volume (the "storage-yield functions").

The great scholar of the Nile, H. E. Hurst, has described his pioneer approach to the study of the biblical sequence of fat years and lean years in Nature and elsewhere. Fiering's book gives an account of the bases of the more extensive studies undertaken at Harvard with the aid of computers. Hurst, for practical reasons arising from the construction of the now High Dam at Aswan, and Feller for theoretical reasons, concentrated on the range of cumulative departures, rolated to the storage volume required for a certain reservoir regulation of river flows. Fiering correctly recognizes the importance of the range and uses it as the main criterion for acceptability of the synthetic series of data which he generates by means of recursive (Markov) processes, with single and with multiple lags (the latter giving support to Hurst's original empirical formula for the range).

The last two chapters discuss the application of decision theory to the design of reservoirs and the generalizations required for the design of systems of several reservoirs.
Written in Fiering's characteristic style, the book is strongly recommended to mathematical and engineering hydrologists and water-resource economists.

P. O. Wolf

\section{CHANGES IN A YEAST CELL}

\section{Aspects of Yeast Metabolism}

Edited by A. K. Mills. (A Guinness Symposium held at the Research Laboratory, St James's Gate, Dublin. Consulting editor: Sir Hans Krebs.) Pp. xiv +345 . (Blackwell: Oxford and Edinburgh, 1968.) 77s. $6 d$.

THIs book contains the papers presented at the second Guinness Symposium which dealt with "Yeast Metabolism". The organizers are to be congratulated on their choice of participants, and in having persuaded them to submit manuscripts for publication so that all biochemists can share in this unique and stimulating exchange of ideas and information. A useful feature of the volume is an edited account of the main points of the discussion which followed the various contributions.

After introductory remarks from Sir Hans Krebs, $H$. Suomalainen reviewed the structure and function of the yeast cell. Particular attention was paid to the plasma membrane, protoplasts and mitochondria and to the location of enzymes in the cell walls. The ability of yeast to synthesize different aroma compounds during fermentation, and the use of gas-liquid chromatography for their analysis were also described.

The important topic of carbohydrate transport in yeasts, and the relation of this process to other aspects of cell metabolism, were described in two papers by A. Kleinzeller and A. Kotyk and by A. Sols. The available evidence indicates that in some species, and with certain sugars, facilitated diffusion takes place, whereas in other cases an active (energy-dependent) mechanism is involved. The second paper describes possible mechanisms for the regulation of the pathways of carbohydrate metabolism. The aldolases and fructose diphosphatases are key enzymes in the glycolytic pathway, and recent comparative studies were described by B. L. Horecker and his co-workers. A final chapter on carbohydrate metabolism by T. O. Wilkén deals with the "Negative Pasteur" effect in yeasts; that is to say, a stimulation of the process of alcoholic fermentation in the presence of oxygen.

The important topic of protein biosynthesis in yeast was reviewed by $H$. O. Halvorson. An outline of the general features of protein synthesis was followed by an account of recent studies on yeast ribosomes and poly. somes, $m$-RNA, and a cell-free system for the incorporation of amino-acids. The related topic of adaptation in yeast was described by $H$. Holzer. Enzymatic regulation, feedback mechanisms and the induction and repression of enzymatic synthesis are included. The incorporation of nucleotides and amino-acids by mitochondrial DNA is then described by $H$. R. Mahler and co-workers.

Two papers are devoted to various aspects of the action of respiratory enzymes in yeast. M. F. Utter and his coworkers describe alterations in the respiratory enzymes of the mitochondria of growing and resting yeast, and the effect of chloramphenicol on the differentiation of the mitochondrial organelle is discussed by A. W. Linnane and his colleagues. Fat metabolism in yeast is covered by an authoritative paper on fatty acid synthetase-a remarkable multi-enzyme complex-by F. Lynen and by an account of yeast phospholipids from R. Letters. The final chapter on "Oxygen, the Creator of Differentia. tion" by $\mathrm{O}$. Warburg is of special philosophical interest to all biochemists.

To summarize, this volume provides a survey of current developments in the major branches of biochemistry, and contains a wealth of experimental information on 